\title{
How to build a mini meteorological station for your school? - A project with a citizen science perspective
}

\author{
Mária Pető ${ }^{1,3}$ and Andrea Király ${ }^{2,3}$ \\ ${ }^{1}$ Székely Mikó Theoretical High School, Sf. Gheorghe, 520003, Romania \\ ${ }^{2}$ ELTE Eötvös Loránd University, Faculty of Science, Budapest, 1053, Hungary \\ ${ }^{3}$ MTA-ELTE Physics Education Research Group, Budapest, 1051, Hungary \\ Correspondence: Mária Pető (rkollegium@ yahoo.com)
}

Received: 24 February 2019 - Revised: 29 May 2019 - Accepted: 10 June 2019 - Published: 26 August 2019

\begin{abstract}
Thermodynamics and electricity are parts of the 10th grade physics curriculum in Romania, but the exciting questions of atmospheric physics and meteorology could be answered if we organize special activities. Linking these topics, educators can create many interesting learning opportunities and try new ways of teaching. This paper is based on a school project and experiment that were used during the last school years in the classroom learning and practical outdoor activities with the Science Club students. The aim of the project is to build a device to measure atmospheric climate variables (e.g. air temperature, air pressure, humidity) and to demonstrate and explain some weather phenomenon. The observations are stored in a database, the data archive and visualization of the data are accessible through a webpage. Students from other schools can get involved in the measurements with their own built devices and can upload their own measurement data to the common database, so we could create a weather map for schools. The whole system is planned as a network of minimeteo stations for students.
\end{abstract}

\section{Introduction}

Learning and studying about the atmosphere, weather, climate change or the greenhouse effect are important elements of environmental education in schools. The Romanian school curriculum (Programa de Fizica pentru gimnaziu, 2017) is incomplete in terms of meteorology or climate issues, it introduces only a few basic concepts (cloud, wind, precipitation) without any explanation; and it does not deal with the theoretical background of the meteorological phenomena.

In Hungary the atmospheric physics is an inherent part of the curriculum of physics, geography and environmental science (Nemzeti Alaptanterv, 2012). Hungarian curriculum (NAT) emphasizes the importance of the integration of the content knowledge of the natural sciences, and atmosphetric physics is a field where this type of thinking is extremely important. The question of the climate change and sustainable development are also important area of the teaching of scientific thinking and the education of socially sensitive citizens (Király et al., 2019). These contents have mostly a descriptive character and the deeper physical reasoning is missing.

In spite of the different syllabuses students are curious about the causes of the observed phenomena. Therefore, they should be properly taught to understand their effects in everyday life. During the lessons, the learners' questions show that it is not always clear that how the theoretical knowledge could be applied directly in everyday practice. Because of this, one of the goals of the Székely Mikó High School Science Club is to organize special activities that meet these desiderata.

One of the most interesting tasks of the last school years was to build a mini meteo station to study some of the parameters that determine the weather. At the same time, the project also aimed to deepen the student's theoretical knowledge of thermodynamics, electricity and geography during hands-on activity. 

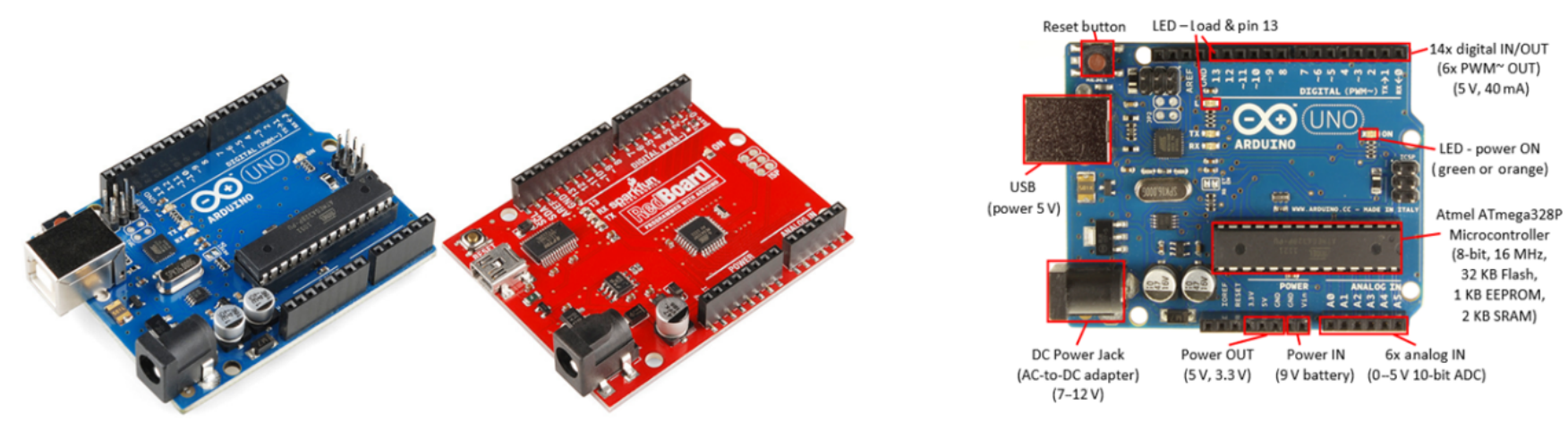

Figure 1. Arduino Uno and Redboard microcontrollers with pin diagram.
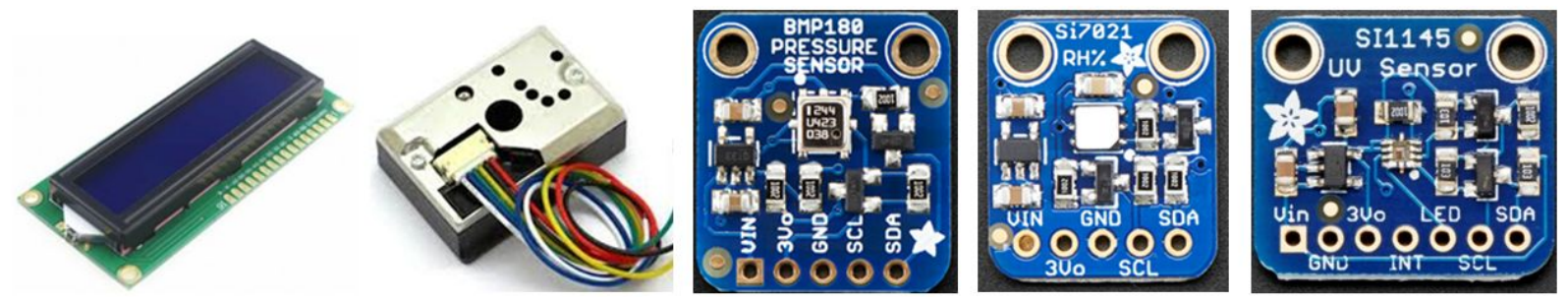

Figure 2. LCD display, dust, pressure, relative humidity and UV index sensors.

\section{Educational approach}

In the Science Club different grades students (8th-12th grade) work together $2 \mathrm{~h}$ in every week on various topics. They participate voluntarily, are very motivated, curious and willing to spend time with learning on informal way. During the working sessions, students are grouped in small teams (4-6 youngsters) with a well-defined task and work together for several weeks from the problem identification to the solution (problem-based learning) (Savery, 2006; Hmelo-Silver, 2004). The tasks are chosen on basis of a preliminary survey, observation or personal experience. A mentor-student (1112th grade) leads each group, who divides the tasks between team members, based on prior knowledge of the subject or in the area, they want to develop themselves (Pető, 2016).

\subsection{Building a meteo station}

In the last year the objectives for the students were to create two different units that measure air temperature, relative humidity, air pressure, atmospheric pollution and UV index. Both of them transmit the measured data to a central unit to analyse them. One of these units has been fixed on the ground (outside of the physics lab's window, in a protected area, Fig. 4b) and the other do measurements during flight on a certain height (like a CanSat). The mobile unit is easy to assemble during a classroom activity and to connect with a radio-transceiver module (built before). The idea of a flying device was born after one of the "CanSat in Europe" competition held by ESA (European Space Agency), where the
Science Club team took part. (For details of such a competition see the ESA CanSat webpage at https://www.esa.int/ Education/CanSat/What_is_a_CanSat, ESA CanSat, 2019.) The students have utilized the experience gained in this contest to build a quadcopter lifted measuring unit. A very small and light device (fit in a coca-soda can) with pressure, temperature, relative humidity, air quality sensors with GPS and altimeter was made to fulfil the task. Both units (the fixed and the flying) are Arduino microcontroller based measuring instruments, which were designed, built and operated by students (Petô, 2014; Petô, 2017a, c). The used Arduino Uno or Redboard (Fig. 1) are open-source electronics platforms with an Atmega328 chip, easy to connect with a large variety of electronic sensors (Margolis, 2011).

The first step in the project is a brainstorming session when the best-fitting device is chosen, the measuring methods and the outcome are also found out. At the beginning stage, the pupils use their creativity to discover the best possible solution to the problem. Meanwhile, they acquire basic knowledge about electrical circuits, measuring principles, Arduino microcontrollers, sensors (e.g. Fig. 2), data collecting and analyzing procedures, programming languages and atmospheric physics.

This is an intense learning phase, where the theoretical knowledge (electric power, current intensity, resistance, Ohm's law, etc.) is applied in a concrete practical situation. Simple circuits are designed and built by the students using few elements: power supply units, a variety of resistor networks, active and passive circuit elements, switches and measuring instruments with suitable accuracy. The result of 

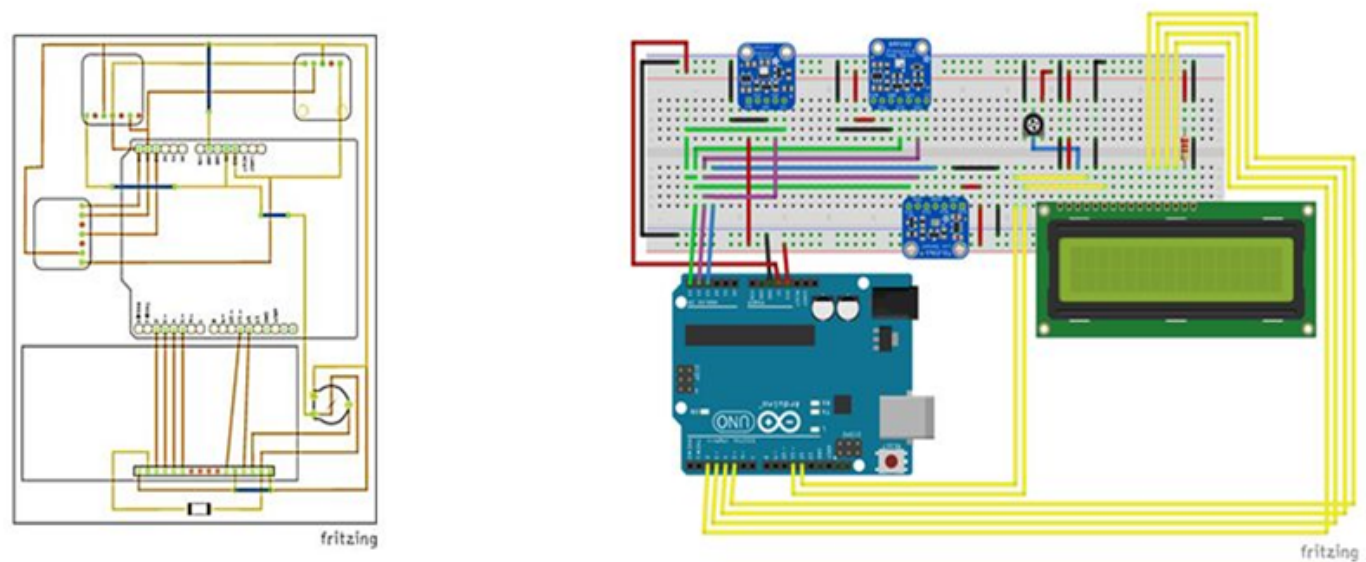

Figure 3. The circuit design and PCB diagram (made by V. V. Áron 11th grade student).
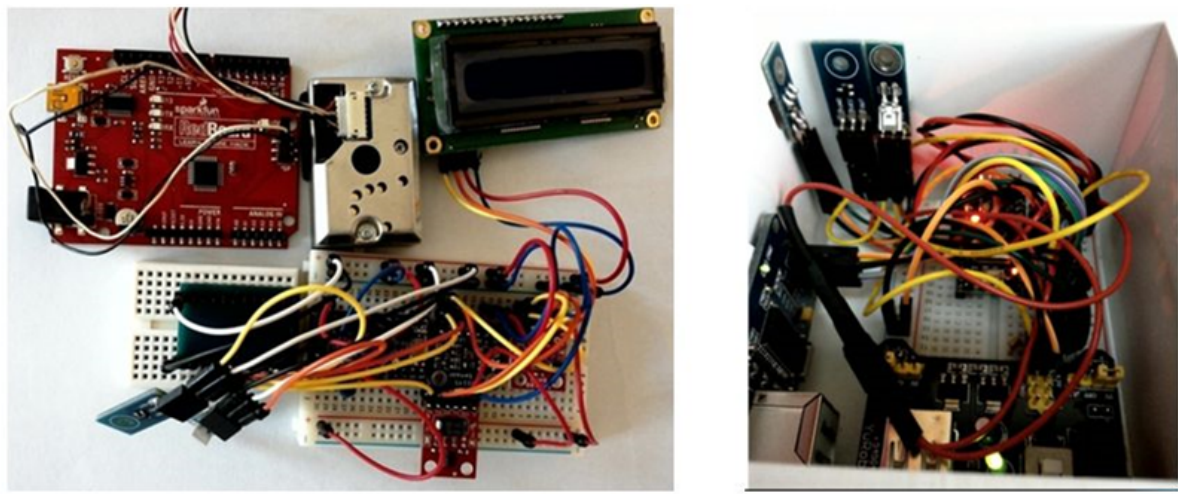

Figure 4. The testing module and the fixed mini meteo station (near the physics lab).

this process is that the learned theories are fixed and, in the meantime, the students are enriched with practical knowledge (Petô, 2016).

Another challenge becomes obvious while designing the circuit (Fig. 3). For the measuring units, a circuit design and a printed circuit board have to be made. Students should consider what kinds of sensors are the most appropriates (based on their electrical characteristics and datasheet) and how to connect them to make an effective measurement. By selecting sensors and power supplies, the planning work will be completed.

The next step is to draw the circuits and to carry out a testing measurement on a breadboard. Based on the results obtained, the circuit structure could be improved, some sensors can be replaced or extended. Meanwhile, attention should be paid to economical use of space, all circuit elements have to function on the planned parameters (in a relatively small place), and these have to be easy controllable.

The younger students use the Fritzing software to design the circuit, learned from their mentors. In the course of the the design process, they will learn the measurement principles of the sensors, the communication protocols and the connection types of the circuit modules. Once the designing and the block diagram for the operating system is completed, one part of the team should prepare the printed circuit boards (PCB) and the sensors for soldering. The teams prepare more than one test unit for learning so they could practice the assembly phases and understand the operating principle. Simultaneously, the other part of the group starts to prepare the proper software (Margolis, 2011; Pető, 2017b, c).

The Arduino library and Arduino IDE are used to write the appropriate software to command the measuring sensors completed by the $\mathrm{C}++$ language learned at IT classes. This creative process is another good opportunity for the student to use the acquired knowledge of computer science classes for a specific practical task.

Data processing and interpretation are very significant elements in understanding the physical background and causeeffect relationships behind the phenomena like the vertical temperature gradient law in the atmosphere, the barometric formula for the pressure, solid pollution distribution in the air, and the relationship between relative humidity and precipitations. 

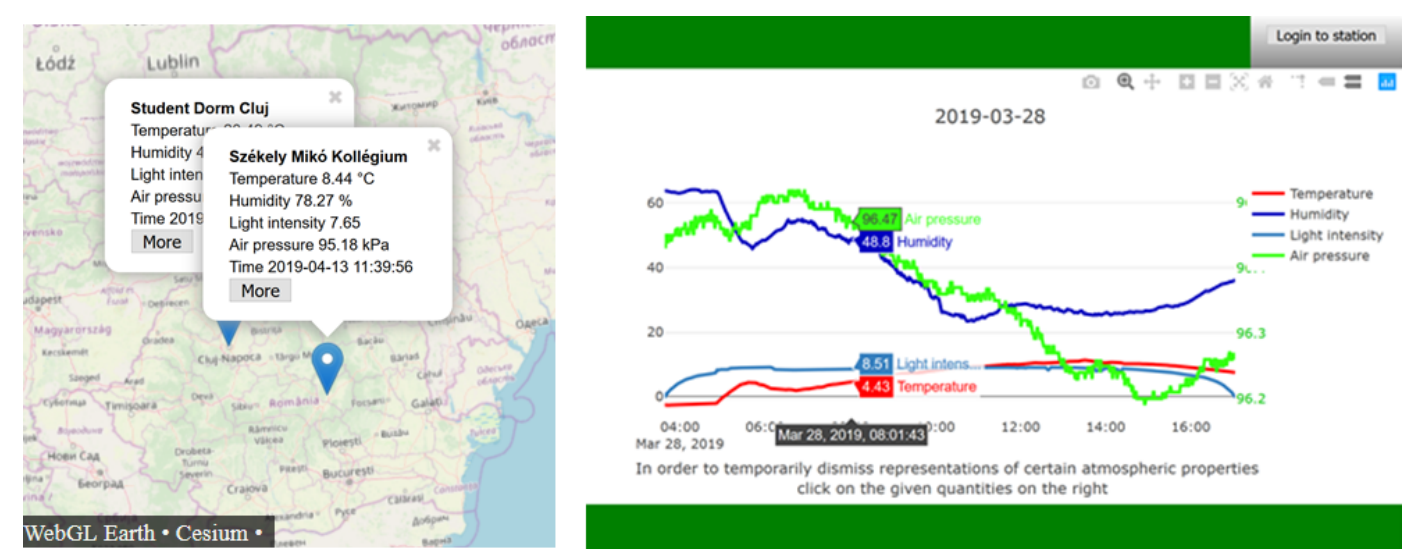

Figure 5. The fixed mini meteo stations website (http://globalweather.000webhostapp.com/index.php, last access: 29 May 2019), by A. Medgyesi, 12th grade student.
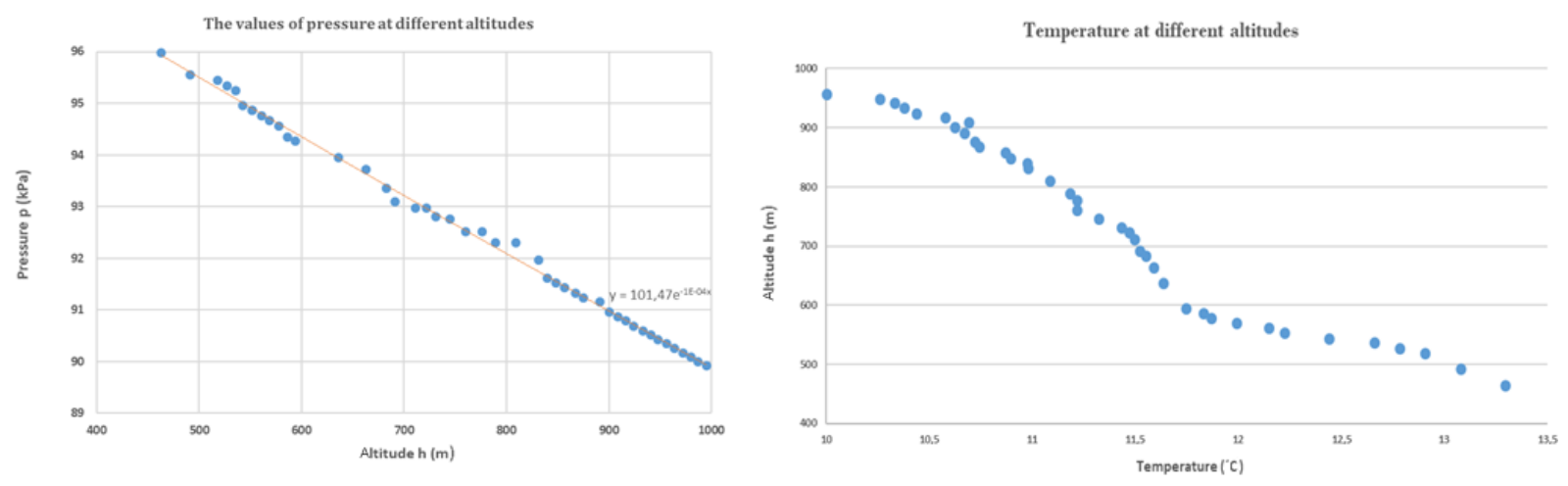

Figure 6. The air pressure and temperature measured by the flying unit at different altitudes.

Another considerable step in data processing is the graphic representation, interpretation and tracking the data over a long period. As a result, the formulated conclusions and answers are much accurate and could be verified, combined with knowledge learned at biology, chemistry or geography classes (Ahrens and Henson, 2016; Marshall and Plumb, 2008; Wallace and Hobbs, 2006).

We often do measurements on hillside near the city with a mobile device. Similar sensors are built into this unit, complemented by a GPS and a radio transmitter. The flying unit is lifted of distinct heights with a quadcopter. The unit send data to a central ground unit using a $433 \mathrm{MHz}$ RF transceiver system (this unit is built at Science Club in advance), measured at a few hundred meters altitude, and the fixed one use a wireless transmitting module. The data recorded by the ground (Fig. 5) and flying modules (Fig. 6) are collected in a dedicated computer database and then are analysed and compared during special activities (Petó, 2014).

\section{Conclusions}

These STEM (Science, Technology, Engineering, and Mathematics) projects (Gonzalez and Kuenzi, 2012) provide the opportunity for students to understand the practical utility of learned theories while being aware of their civil responsibility for environmental protection. The Science Club activities are true engineering works, where students can use their creative potential and innovative ideas in an informal learning situation. Our survey applied at the end of project shows that, despite the many challenges that have to be solved, this is a funny, enjoyable form of learning for students and they are very motivated to participate.

In the near future, a network of mini meteo stations by more schools will be set up, and the data of each station will appear on a common website. The new stations could join after a simple registration process, and the database of the measurements is open accessed for interested potential users to analyse or download data. The database archive has to be improved further, while the meteo-network needs a statistical data processing facility as well. 
Data availability. There were no data analyzed in this paper. The data used for illustrations are available via the mini meteo stations website.

Author contributions. MP performed several CanSat and Arduino projects with the Science Club students. The idea of mini meteo stations network has came from AK. MP wrote the first draft of the article. The final version was completed by AK.

Competing interests. The authors declare that they have no conflict of interest.

Special issue statement. This article is part of the special issue "18th EMS Annual Meeting: European Conference for Applied Meteorology and Climatology 2018”. It is a result of the EMS Annual Meeting: European Conference for Applied Meteorology and Climatology 2018, Budapest, Hungary, 3-7 September 2018.

Acknowledgements. This work has received funding from the Hungarian Academy of Sciences.

Financial support. This research has been supported by the Content Pedagogy Research Program of the Hungarian Academy of Sciences (grant no. 471027).

Review statement. This paper was edited by Tomas Halenka and reviewed by Lars-Jochen Thoms and Andras Tel.

\section{References}

Ahrens, C. D. and Henson, R.: Meteorology Today. An Introduction to Weather, Climate, and the Environment, Cengage Learning, Boston, USA, 2016.

ESA CanSat: Cansats in Europe. What is a CanSat?, available at: https://www.esa.int/Education/CanSat/What_is_a_CanSat, last access: 29 May 20192019.

Gonzalez, H. B. and Kuenzi, J. J.: Science, Technology, Engineering, and Mathematics (STEM) Education: A Primer, CRS Report for Congress 7-5700, R42642, available at: https://fas.org/ sgp/crs/misc/R42642.pdf (last access: 29 May 2019), 2012.

Hmelo-Silver, C. E.: Problem-Based Learning: What and How Do Students Learn?, Educ. Psychol. Rev., 16, 235-266, https://doi.org/10.1023/B:EDPR.0000034022.16470.f3, 2004.
Király, A., Kárpáti, A., and Tasnádi, P.: Responsibility of Teachers: The SSIBL Model in Hungary, in: Concepts, Strategies and Models to Enhance Physics Teaching and Learning, edited by: McLoughlin, E. and van Kampen, P., Springer Nature Switzerland AG, Cham, ISBN 978-3-030-18136-9 (in print), eBook: ISBN 978-3-030-18137-6, https://doi.org/10.1007/9783-030-18137-6_13, 2019.

Margolis, M.: Arduino Cookbook. Recipes to Begin, Expand, and Enhance Your Projects, O'Reilly, Beijing, Cambridge, Farnham, Köln, Sebastopol, Tokyo, ISBN 978-0-596-80247-9, 2011.

Marshall, J. and Plumb, R. A.: Atmosphere, Ocean and Climate Dynamics: An Introductory Text, in: International Geophysics Series, 1st Edn., Elsevier, Oxford, 2008.

Nemzeti Alaptanterv: https://net.jogtar.hu/jogszabaly?docid= a1200110.kor (last access: 29 May 2019), in: Új Pedagógiai Szemle, 2012, Vol. 1-2-3, available at: http://folyoiratok.ofi. hu/uj-pedagogiai-szemle/lapszamok/2012-1-2-3 (last access: 29 May 2019), 2012.

Pető, M.: Experiments with Cansat, in: Conference Proceedings, in: The International Conference on Physics Education; Active learning in a changing world of new technologies, ICPEEPEC-2013, edited by: Dvořák, L. and Koudelková, V., Prague, ISBN 978-80-7378-266-5, 766-774, 2014.

Pető, M.: Robotics, CANSAT, ARDUINO - physics at Székely Mikó Science Club, in: Teaching Physics Innovatively - New Learning Environments and Methods in Physics Education, ebook, edited by: Király, A. and Tél, T., ELTE Eötvös Loránd University, Budapest, Hungary, ISBN 978-963-284-815-0, 169174, 2016.

Petô, M.: Space research and mini-satellites in secondary high school. (HSPACE2017-FP-43) in: Selected papers of the 3rd International Conference on Research, Technology and Education of Space (H-SPACE-2017), edited by: Bacsárdi, L. and Kovács, K., Budapest, ISBN 978-963-7367-16-8, 44-48, 2017 a.

Petô, M.: Robotics and measuring devices based on Arduino applications, in: 21st International Conference on Multimedia in Physics Teaching and Learning (MPTL-2017) Book of Abstracts, The Open University, Milton Keynes, UK, $2017 \mathrm{~b}$.

Pető, M.: Space Research and Mini-satellites in Secondary High School, Int. J. Astrophys. Space Sci., 5, 71-78, https://doi.org/10.11648/j.ijass.20170505.11, 2017c.

Programa de Fizica pentru gimnaziu: available at: http://programe. ise.ro/Portals/1/Curriculum/2017-progr/25-Fizica.pdf (last access: 29 May 2019); Programa de fizica pentru clasa a X-a, available at: http://oldsite.edu.ro/index.php/articles/6263 (last access: 29 May 2019), 2017.

Savery, J. R.: Overview of Problem-based Learning: Definitions and Distinctions, Interdisciplin. J. Probl.-Bas. Learn., 1, 9-20, https://doi.org/10.7771/1541-5015.1002, 2006.

Wallace, J. M. and Hobbs, P. V.: Atmospheric Science. An introductory survey, 2nd Edn., Elsevier, Washington, ISBN 0-12-732951X, 2006. 